\title{
Establishing New Regression Equations for Obtaining the Diffuse Solar Radiation in Sakarya (Turkey)
}

\author{
Ceyda Aksoy TIRMIKÇI, Cenk YAVUZ
}

\begin{abstract}
In this paper diffuse solar radiation component is investigated for Sakarya city (Turkey). For this purpose, 17 diffuse solar radiation equations correlating the diffuse fraction with the clearness index and/or the sunshine fraction are selected from the literature. The predictions obtained from the selected equations are utilized to determine the regression constants of the new equations. In conclusion, the best equation for the city is introduced by performing statistical analysis.
\end{abstract}

Keywords: clearness index; diffuse fraction; diffuse solar radiation equations; statistical analysis; sunshine fraction

\section{INTRODUCTION}

The latest energy report indicates that Turkey is heavily dependent on imported fossil fuels for meeting its rising energy demands $[1,2]$. Thus it is vital to break this dependency for providing a sustainable growth. At this point, solar energy becomes prominent among all the alternative energy sources due to the favourable geographical location of the country.

The accuracy of the solar data measurements is vital in designing and analysing solar energy systems [3]. Today global solar radiation for a specific location is easily recorded in many countries. However diffuse solar radiation measurement is available in only few countries. Diffuse solar radiation data is required for determining the amount of the total solar radiation on an inclined surface which provides information about the system performance [4]. Therefore it is necessary to develop mathematical equations based on meteorological data for estimating the diffuse component. Liu and Jordan developed the first diffuse solar radiation equation defining the diffuse fraction in terms of the clearness index [5]. Then several researchers have developed empirical equations based on this equation [6-31]. In these equations the solar diffuse fraction and/or the solar diffuse coefficient are introduced in terms of the clearness index [7-9], the sunshine fraction [10-14] and both [15-19]. Al-Mohammad calculated solarradiation components starting from the simple Angström formula [21]. El-Sebaii et al. used the clearness index, the sunshine fraction, the ambient temperature, the cloud cover and the relative humidity as input data in their equation [23]. They divided the input data into two parts. The first part, the data between 1996 and 2004, is used to develop the equation while the second part, the data between 2005 and 2007, is used to evaluate the results of the proposed equations. Elminir et al. utilized artificial neural network (ANN) technique in their work to estimate the diffuse component [24]. They observed that the equations by ANN technique give better results compared to the equations by regression analysis technique.

The solar radiation measurement stations in Turkey are all capable of measuring the global component. But only few of them measure the diffuse component at present. Therefore, many Turkish researchers have developed several equations for investigating the diffuse solar radiation for specific locations of Turkey based on the available solar data [26-31]. Aras et al. established twelve new empirical equations from twenty current equations to determine the best diffuse fraction equation for Turkey's Central Anatolia Region [26]. Tarhan and Sarı analysed solar radiation data over the five provinces of the Central Black Sea Region of Turkey [27]. They developed two new equations: a cubic polynomial equation and a quadratic polynomial equation. They observed that the new equations give good accuracy for the region. Ulgen and Hepbasli established eight new equations for predicting the diffuse component for three big cities of Turkey [28]. Tiris et al. used measured meteorological data to develop new empirical equations for correlating the solar radiation components for Gebze city, Turkey [29]. Bakırcı analysed the measured solar data for the eight provinces of Turkey to establish new empirical diffuse solar radiation equations [30]. He used fifteen current equations from the open literature and meteorological data of the provinces to develop these equations. By performing statistical analysis he observed that the proposed equations agree with the obtained average values of the selected fifteen equations. Ulgen and Hepbasli recorded the diffuse solar radiation from 1994 to 1998 for İzmir city, Turkey [31]. They observed that the predictions of their new equations fit the measured data better than the current equations.

In this paper available measured solar radiation data and the current diffuse solar radiation equations are analysed to express the diffuse fraction for Sakarya city. Nine new diffuse solar equations by the clearness index and/or the sunshine fraction are developed respectively. In conclusion the estimates of all the equations are compared statistically and the most accurate equation of all is established.

\section{REVIEWING CURRENT DIFFUSE SOLAR RADIATION EQUATIONS}

In this section the current equations based on the clearness index and/or the sunshine fraction are examined. The clearness index is the global solar radiation $(H)$ divided by the extra-terrestrial solar radiation $\left(H_{0}\right)$, the sunshine fraction is the hours of sunshine $(S)$ divided by the maximum hours of sunshine $\left(S_{0}\right)$ and the diffuse fraction is the diffuse solar radiation $\left(H_{\mathrm{d}}\right)$ divided by the global solar radiation $(H)$. Seventeen of the commonly adapted equations from the literature are as follows: 
i) Equations expressing $\left(H_{\mathrm{d}} / H\right)$ in terms of $\left(S / S_{0}\right)$ :

Eq. (1) [14]:

$\frac{H_{\mathrm{d}}}{H}=0.6603-0.5272 \times\left(\frac{S}{S_{0}}\right)$

Eq. (2) [26]:

$\frac{H_{\mathrm{d}}}{H}=0.663-0.4883 \times\left(\frac{S}{S_{0}}\right)$

Eq. (3) [10]:

$\frac{H_{\mathrm{d}}}{H}=0.791-0.635 \times\left(\frac{S}{S_{0}}\right)$

Eq. (4) [14]:

$\frac{H_{\mathrm{d}}}{H}=0.7434-0.8203 \times\left(\frac{S}{S_{0}}\right)+0.2454 \times\left(\frac{S}{S_{0}}\right)^{2}$

Eq. (5) [26]:

$\frac{H_{\mathrm{d}}}{H}=0.6492-0.4323 \times\left(\frac{S}{S_{0}}\right)-0.0512 \times\left(\frac{S}{S_{0}}\right)^{2}$

Eq. (6) [26]:

$\frac{H_{\mathrm{d}}}{H}=0.5562+0.1536 \times\left(\frac{S}{S_{0}}\right)-1.2027 \times\left(\frac{S}{S_{0}}\right)^{2}+$

$+0.7122 \times\left(\frac{S}{S_{0}}\right)^{3}$

(6)

ii) Equations expressing $\left(H_{\mathrm{d}} / H\right)$ in terms of $\left(H / H_{0}\right)$ :

Eq. (7) [7]:

$\frac{H_{\mathrm{d}}}{H}=1.00-1.13 \times\left(\frac{H}{H_{0}}\right)$

Eq. (8) [26]:

$\frac{H_{\mathrm{d}}}{H}=1.0212-1.1672 \times\left(\frac{H}{H_{0}}\right)$

Eq. (9) [28]:

$\frac{H_{\mathrm{d}}}{H}=0.6772-0.4841 \times\left(\frac{H}{H_{0}}\right)$

Eq. (10) [26]:

$\frac{H_{\mathrm{d}}}{H}=1.1244-1.5582 \times\left(\frac{H}{H_{0}}\right)+0.3635 \times\left(\frac{H}{H_{0}}\right)^{2}$

Eq. (11) [27]:

$\frac{H_{\mathrm{d}}}{H}=0.9885-1.4276 \times\left(\frac{H}{H_{0}}\right)+0.5679 \times\left(\frac{H}{H_{0}}\right)^{2}$
Eq. (12) [27]:

$\frac{H_{\mathrm{d}}}{H}=1.027-1.6582 \times\left(\frac{H}{H_{0}}\right)+1.1018 \times\left(\frac{H}{H_{0}}\right)^{2}-$

$-0.4019 \times\left(\frac{H}{H_{0}}\right)^{3}$

iii) Equations expressing $\left(H_{\mathrm{d}} / H\right)$ in terms of $\left(H / H_{0}\right)$ and $\left(S / S_{0}\right)$ :

Eq. (13) [16]:

$\frac{H_{\mathrm{d}}}{H}=1.194-0.838 \times\left(\frac{H}{H_{0}}\right)-0.446 \times\left(\frac{S}{S_{0}}\right)$

Eq. (14) [17]:

$\frac{H_{\mathrm{d}}}{H}=1.00-0.858 \times\left(\frac{H}{H_{0}}\right)-0.235 \times\left(\frac{S}{S_{0}}\right)$

Eq. (15) [15]:

$\frac{H_{\mathrm{d}}}{H}=0.945-0.675 \times\left(\frac{H}{H_{0}}\right)-0.166 \times\left(\frac{H}{H_{0}}\right)^{2}-$

$-0.173 \times\left(\frac{S}{S_{0}}\right)-0.079 \times\left(\frac{S}{S_{0}}\right)^{2}$

Eq. (16) [15]:

$\frac{H_{\mathrm{d}}}{H}=0.747-1.502 \times\left(\frac{H}{H_{0}}\right)-4.956 \times\left(\frac{H}{H_{0}}\right)^{2}+$

$+0.173 \times\left(\frac{H}{H_{0}}\right)^{3}-1.004 \times\left(\frac{S}{S_{0}}\right)+1.747 \times\left(\frac{S}{S_{0}}\right)^{2}-$

$-1.226 \times\left(\frac{S}{S_{0}}\right)^{3}$

Eq. (17) [18]:

$\frac{H_{\mathrm{d}}}{H}=0.9593-0.8713 \times\left(\frac{H}{H_{0}}\right)+0.29191 \times\left(\frac{H}{H_{0}}\right)^{2}-$

$-0.0979 \times\left(\frac{H}{H_{0}}\right)^{3}-0.28419 \times\left(\frac{S}{S_{0}}\right)+0.02653 \times\left(\frac{S}{S_{0}}\right)^{2}-$

$-0.02083 \times\left(\frac{S}{S_{0}}\right)^{3}$

\section{DATA AND METHODOLOGY}

The global solar radiation $(H)$ and hours of sunshine $(S)$ are obtained from the solar energy potential atlas by Turkey Renewable Energy Head Office (Tab. 1).

The extra-terrestrial solar radiation $\left(H_{0}\right)$ and maximum possible hours of sunshine $\left(S_{0}\right)$ are calculated from mathematical expressions respectively [32-34]: 


$$
\begin{aligned}
& H_{0}=\frac{24 \times 3600}{\pi} \times G_{\mathrm{sc}} \times\left(1+0.33 \times \cos \frac{360 \times n_{\text {day }}}{365}\right) \times \\
& \times\left(\cos \phi \times \cos \delta \times \sin w_{\mathrm{s}}+\frac{\pi \times w_{\mathrm{s}}}{180} \times \sin \phi \times \sin \delta\right) \\
& S=\frac{2}{15} \times w_{\mathrm{s}}
\end{aligned}
$$

where $G_{\text {sc }}$ is the solar constant (equals $1367 \mathrm{~W} / \mathrm{m}^{2}$ ), $n_{\text {day }}$ is the number of the day of the year and $\phi$ is the latitude. $\delta$ is solar declination and $w_{\mathrm{s}}$ is the sunrise hour angle for horizontal surface defined as:

$$
\begin{aligned}
& \delta=23.45 \times \sin \left(\frac{n_{\text {day }}+284}{365} \times 360\right) \\
& w_{\mathrm{s}}=\cos ^{-1}(-\tan \varphi \times \tan \delta)
\end{aligned}
$$

The diffuse solar radiation is obtained by averaging the results of the selected equations for the city. Then the following equations are utilized to develop new diffuse solar equations fitting all the data obtained:

i) Equations expressing $\left(H_{\mathrm{d}} / H\right)$ in terms of $\left(S / S_{0}\right)$ :

$$
\frac{H_{\mathrm{d}}}{H}=c_{0}+c_{1} \times\left(\frac{S}{S_{0}}\right)+c_{2} \times\left(\frac{S}{S_{0}}\right)^{2}+c_{3} \times\left(\frac{S}{S_{0}}\right)^{3}
$$

ii) Equations expressing $\left(H_{\mathrm{d}} / H\right)$ in terms of $\left(H / H_{0}\right)$ :

$$
\frac{H_{\mathrm{d}}}{H}=c_{0}+c_{1} \times\left(\frac{H}{H_{0}}\right)+c_{2} \times\left(\frac{H}{H_{0}}\right)^{2}+c_{3} \times\left(\frac{H}{H_{0}}\right)^{3}
$$

iii) Equations expressing $\left(H_{\mathrm{d}} / H\right)$ in terms of $\left(H / H_{0}\right)$ and $\left(S / S_{0}\right)$ :

$$
\begin{aligned}
& \frac{H_{\mathrm{d}}}{H}=c_{0}+c_{1} \times\left(\frac{H}{H_{0}}\right)+c_{2} \times\left(\frac{H}{H_{0}}\right)^{2}+c_{3} \times\left(\frac{H}{H_{0}}\right)^{3}+ \\
& +c_{4} \times\left(\frac{S}{S_{0}}\right)+c_{5} \times\left(\frac{S}{S_{0}}\right)^{2}+c_{6} \times\left(\frac{S}{S_{0}}\right)^{3}
\end{aligned}
$$

where $c_{0}, c_{1}, c_{2}, c_{3}, c_{4}, c_{5}$ and $c_{6}$ express the regression constants determined by the regression analysis technique [35].

Finally, the accuracy of all equations including the selected equations from the literature is evaluated using the statistical indicators below:

Mean bias error:

$$
M B E=\frac{1}{x} \sum_{i=1}^{x}\left(E V_{i}-M V_{i}\right)
$$

Mean absolute percentage error:
$M A P E=\frac{1}{x} \sum_{i=1}^{x}\left|\frac{E V_{i}-M V_{i}}{M V_{i}}\right|$

Mean absolute bias error:

$$
M A B E=\frac{1}{x} \sum_{i=1}^{x}\left|E V_{i}-M V_{i}\right|
$$

Root mean square error:

$$
R M S E=\sqrt{\frac{1}{x} \sum_{i=1}^{x}\left(E V_{i}-M V_{i}\right)^{2}}
$$

Coefficient of determination:

$$
R^{2}=\frac{\sum_{i=1}^{x}\left(E V_{i}-E V_{a}\right) \cdot\left(M V_{i}-M V_{a}\right)}{\sqrt{\left[\sum_{i=1}^{x}\left(E V_{i}-E V_{a}\right)^{2}\right] \cdot\left[\sum_{i=1}^{x}\left(M V_{i}-M V_{a}\right)^{2}\right]}}
$$

t-statistics:

$$
t=\sqrt{\frac{(n-1) M B E^{2}}{R M S E^{2}-M B E^{2}}}
$$

where $x$ is the sample size, $n-1$ is the degrees of freedom, $E V_{i}$ is the $i^{\text {th }}$ estimated value, $M V_{i}$ is the $i^{\text {th }}$ measured value, $E V_{a}$ is the average of the estimated values, $M V_{a}$ is the average of the measured values. All the indicators except the $R^{2}$ take small values around "zero" while the absolute $R^{2}$ takes values around " 1 " in suitable equations. Here the $t$ is used additionally to overcome the inadequacy of the separate utilization of the $M B E$ and RMSE [36]. It is better to select the equations with smaller $\mathrm{t}$ values when the equations give similar results for $M B E$ and $R M S E$.

\section{RESULTS AND DISCUSSIONS}

Based on the data in section 3, the regression coefficients in Eqs. (22), (23) and (24) are obtained by performing the regression analysis technique:

i) Equations expressing $\left(H_{\mathrm{d}} / H\right)$ in terms of $\left(S / S_{0}\right)$ :

$$
\begin{aligned}
\frac{H_{\mathrm{d}}}{H} & =0.7490-0.5512 \times\left(\frac{S}{S_{0}}\right) \\
\frac{H_{\mathrm{d}}}{H} & =0.9795-1.4843 \times\left(\frac{S}{S_{0}}\right)+0.8848 \times\left(\frac{S}{S_{0}}\right)^{2}
\end{aligned}
$$

$$
\begin{aligned}
& \frac{H_{\mathrm{d}}}{H}=0.9903-1.5515 \times\left(\frac{S}{S_{0}}\right)+1.0193 \times\left(\frac{S}{S_{0}}\right)^{2}- \\
& -0.0867 \times\left(\frac{S}{S_{0}}\right)^{3}
\end{aligned}
$$


ii) Equations expressing $\left(H_{\mathrm{d}} / H\right)$ in terms of $\left(H / H_{0}\right)$ :

$$
\begin{aligned}
& \frac{H_{\mathrm{d}}}{H}=0.9576-1.0956 \times\left(\frac{H}{H_{0}}\right) \\
& \frac{H_{\mathrm{d}}}{H}=0.4676+1.2232 \times\left(\frac{H}{H_{0}}\right)-2.6735 \times\left(\frac{H}{H_{0}}\right)^{2}
\end{aligned}
$$

$$
\begin{aligned}
& \frac{H_{\mathrm{d}}}{H}=2.7357-14.7572 \times\left(\frac{H}{H_{0}}\right)+34.9699 \times\left(\frac{H}{H_{0}}\right)^{2}- \\
& -29.1629 \times\left(\frac{H}{H_{0}}\right)^{3}
\end{aligned}
$$

iii) Equations expressing $\left(H_{\mathrm{d}} / H\right)$ in terms of $\left(H / H_{0}\right)$ and $\left(S / S_{0}\right)$ :

$$
\frac{H_{\mathrm{d}}}{H}=0.8695-0.5887 \times\left(\frac{H}{H_{0}}\right)-0.2711 \times\left(\frac{S}{S_{0}}\right)
$$

$$
\begin{aligned}
& \frac{H_{\mathrm{d}}}{H}=0.8782-0.6422 \times\left(\frac{H}{H_{0}}\right)+0.0638 \times\left(\frac{H}{H_{0}}\right)^{2}- \\
& -0.2611 \times\left(\frac{S}{S_{0}}\right)-0.0107 \times\left(\frac{S}{S_{0}}\right)^{2}
\end{aligned}
$$

$$
\begin{aligned}
& \frac{H_{\mathrm{d}}}{H}=0.8675-0.5392 \times\left(\frac{H}{H_{0}}\right)-0.1645 \times\left(\frac{H}{H_{0}}\right)^{2}+ \\
& +0.1660 \times\left(\frac{H}{H_{0}}\right)^{3}-0.2877 \times\left(\frac{S}{S_{0}}\right)+0.0404 \times\left(\frac{S}{S_{0}}\right)^{2}- \\
& -0.0314 \times\left(\frac{S}{S_{0}}\right)^{3}
\end{aligned}
$$

Table 1 Monthly mean daily global solar radiation $H\left(\mathrm{MJ} / \mathrm{m}^{2}\right)$, hours of sunshine $S(\mathrm{~h})$ of Sakarya

\begin{tabular}{|c|c|c|c|c|c|c|c|c|c|c|c|c|}
\hline Months & January & February & March & April & May & June & July & August & September & October & November & December \\
\hline$H$ & 5.112 & 8.244 & 11.808 & 15.876 & 20.304 & 21.636 & 21.024 & 18.972 & 15.0840 & 10.296 & 6.0840 & 4.428 \\
\hline$S$ & 3.20 & 4.23 & 5.01 & 6.33 & 8.39 & 9.72 & 10.35 & 9.56 & 8.01 & 5.53 & 4.05 & 3.09 \\
\hline
\end{tabular}

Table 2 The $M B E\left(\mathrm{MJ} / \mathrm{m}^{2}\right), \operatorname{MAPE}(\%), \operatorname{MABE}\left(\mathrm{MJ} / \mathrm{m}^{2}\right), R M S E\left(\mathrm{MJ} / \mathrm{m}^{2}\right), R^{2}$ and $t$-stat values for the current equations (1)-(17) and the equations developed in this

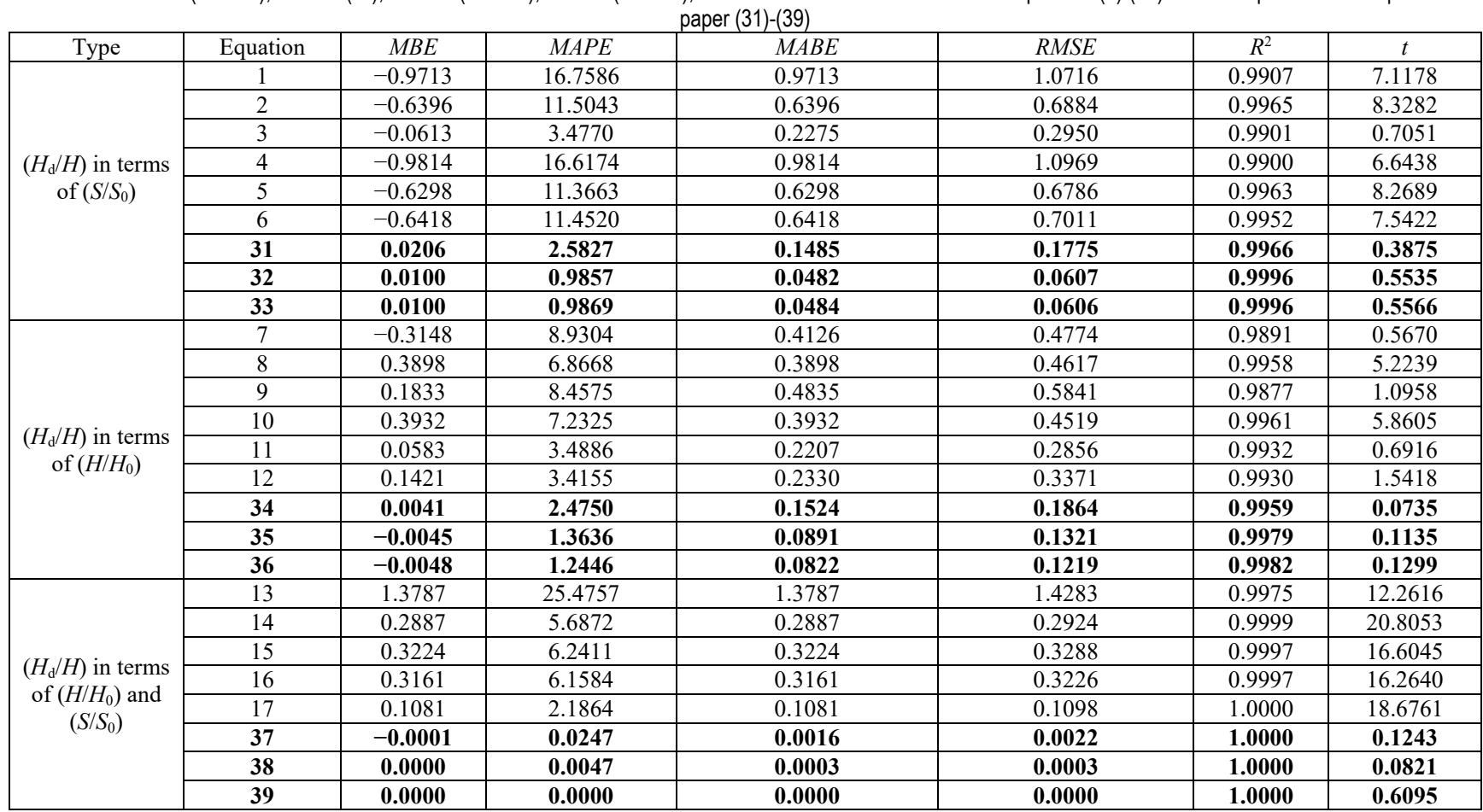

The performance of these new equations (31)-(39): they are all compared with the performance of the seventeen equations selected from the literature (1)-(17) by means of different statistical indicators presented in Tab. 1 . The results indicate that the performance of the new equations developed in this paper is better than the performance of the existing equations. However the equations expressing $\left(H_{\mathrm{d}} / H\right)$ in terms of $\left(H / H_{0}\right)$ and $\left(S / S_{0}\right)$ give the best results among all. The $t$-stat is used as the determining indicator between these equations since the other indicators are almost the same. Thus, it is determined that the Eq. (38) is the most accurate equation for Sakarya city.

\section{CONCLUSION}

Solar energy potential in Turkey is adequate to meet all the energy demand of the country. For utilizing this 
potential efficiently, it is essential to obtain accurate solar data. Unfortunately, it is not possible for most of the cities in Turkey, since only few stations are able to make diffuse solar radiation measurements. To overcome this matter, researchers have proposed mathematical equations for obtaining proper estimates for the diffuse component for some cities. However, there is no measured or predicted diffuse solar radiation data for Sakarya city.

In this paper, new diffuse solar radiation equations are developed for the city by utilizing the current studies from the literature. Based on statistical analysis, the Eq. (38) is introduced as the most accurate equation for the city:

$$
\begin{aligned}
& \frac{H_{\mathrm{d}}}{H}=0.8782-0.6422 \times\left(\frac{H}{H_{0}}\right)+0.0638 \times\left(\frac{H}{H_{0}}\right)^{2}- \\
& -0.2611 \times\left(\frac{S}{S_{0}}\right)-0.0107 \times\left(\frac{S}{S_{0}}\right)^{2}
\end{aligned}
$$

From this result, it can be concluded that both the clearness index and the sunshine fraction are required for estimating the diffuse solar radiation accurately for Sakarya city and the other cities with the same latitude and meteorological conditions in the world.

\section{Acknowledgements}

This work is supported by Sakarya University Scientific Research Projects Unit within the project number 2015-50-02-028.

\section{REFERENCES}

[1] (2014). World Energy Council Turkish National Committee. Energy Report 2013.

[2] Beskirli, M., Hakli, H., \& Kodaz, H. (2017). The energy demand estimation for Turkey using differential evolution algorithm. Sadhana, 42(10), 1705-1715. https://doi.org/10.1007/s12046-017-0724-7

[3] Xue, X. (2017). Prediction of daily diffuse solar radiation using artificial neural networks. International Journal of Hydrogen Energy, 42(47), 28214-28221. https://doi.org/10.1016/j.jijhydene.2017.09.150

[4] Yadav, P. \& Chandel, S. S. (2014). Comparative Analysis of Diffused Solar Radiation Models for Optimum Tilt Angle Determination for Indian Locations. Applied Solar Energy, 50(1), 53-59. https://doi.org/10.3103/S0003701X14010137

[5] Liu, B. Y. H. \& Jordan, R. C. (1960). The relationship and characteristics distribution of direct, diffuse and total radiation. Sol Energy, 4(3), 1-19. https://doi.org/10.1016/0038-092X(60)90062-1

[6] Despotovic, M., Nedic, V., Despotovic, D., \& Cvetanovic, S. (2016). Evaluation of empirical models for predicting monthly mean horizontal diffuse solar radiation. Renewable and Sustainable Energy Reviews, 56(1), 246-260. https://doi.org/10.1016/j.rser.2015.11.058

[7] Page, J. K. (1961). The estimation of monthly mean values of daily total short wave radiation on vertical and inclined surface from sunshine records for latitudes $40 \mathrm{~N}-40 \mathrm{~S}$. Proceedings of UN Conference on New Sources of Energy 1961, 4(598), 378-390.

[8] Oliveira, A. P., Escobedo, J. F., Machado, A. J., Soares, J. (2002). Correlation models of diffuse solar-radiation applied to the city of Saõ Paulo, Brazil. Applied Energy, 71(1), 5973. https://doi.org/10.1016/S0306-2619(01)00040-X

[9] Jacovides, C. P., Tymvious, F. S., Assimakopoulos, V. D., \& Kaltsounides, N. A. (2006). Comparative study of various correlations in estimating hourly diffuse fraction of global solar radiation. Renew Energy, 31(1), 2492-2504. https://doi.org/10.1016/j.renene.2005.11.009

[10] Iqbal, M. (1979). Correlation of average diffuse and beam radiation with hours of bright sunshine. Solar Energy, 23(2), 169-173. https://doi.org/10.1016/0038-092X(79)90118-X

[11] Lewis, G. (1983). Diffuse irradiation over Zimbabwe. Sol Energy, 31(1), 125-128. https://doi.org/10.1016/0038-092X(83)90043-9

[12] Pandey, C. K. \& Katiyar, A. K. (2009). A comparative study to estimate daily diffuse solar radiation over India. Energy, 34(1), 1792-1796. https://doi.org/10.1016/j.energy.2009.07.026

[13] Khahro, S. F., Tabassum, K., Talpur, S., Alvi, M. B., Liao, X., \& Dong, L. (2015). Evaluation of solar energy resources by establishing empirical models for diffuse solar radiation on tilted surface and analysis for optimum tilt angle for a prospective location in southern region of Sindh, Pakistan. Electrical Power and Energy Systems, 64(1), 1073-1080. https://doi.org/10.1016/j.ijepes.2014.09.001

[14] Barbaro, S., Cannata, G., Coppolino, S., Leone, C., \& Sinagra, E. (1981). Diffuse solar radiation statistics for Italy. Solar Energy, 26(1), 429-435. https://doi.org/10.1016/0038-092X(81)90222-X

[15] Jiang, Y. (2009). Estimation of monthly mean daily diffuse radiation in China. Applied Energy, 86(1), 458-464. https://doi.org/10.1016/j.apenergy.2009.01.002

[16] Gopinathan, K. K. (1988). Computing the monthly mean daily diffuse radiation from clearness index and percent possible sunshine. Sol Energy, 41(4), 379-385. https://doi.org/10.1016/0038-092X(88)90034-5

[17] Erbs, D. G., Klein, S. A., \& Duffie, J. A. (1982). Estimation of the diffuse radiation fraction for hourly, daily and monthly average global radiation. Solar Energy, 28(1), 293-302. https://doi.org/10.1016/0038-092X(82)90302-4

[18] Khorasanizadeh, H., Mohammadi, K., \& Mostafaeipour, A. (2014). Establishing a diffuse solar radiation model for determining the optimum tilt angle of solar surfaces in Tabass, Iran. Energy Conversion and Management, 78(1), 805-814. https://doi.org/10.1016/j.enconman.2013.11.048

[19] Sabzpooshani, M. \& Mohammadi, K. (2014). Establishing new empirical models for predicting monthly mean horizontal diffuse solar radiation in city of Isfahan, Iran. Energy, 69(1), 571-577. https://doi.org/10.1016/j.energy.2014.03.051

[20] Elminir, H. K. (2007). Experimental and theoretical investigation of diffuse solar radiation: Data and models quality tested for Egyptian sites. Energy, 32(1), 73-82. https://doi.org/10.1016/j.energy.2006.01.020

[21] Al-Mohammad, A. (2004). Global, direct and diffuse solarradiation in Syria. Applied Energy, 79(1), 191-200. https://doi.org/10.1016/j.apenergy.2003.12.011

[22] Jamil, B. \& Akhtar, N. (2017). Estimation of diffuse solar radiation in humid-subtropical climatic region of India: Comparison of diffuse fraction and diffuse coefficient models. Energy, 131(1), 149-164. https://doi.org/10.1016/j.energy.2017.05.018

[23] El-Sebaii, A. A., Al-Hazmi, F. S., Al- Ghamdi, A. A., \& Yaghmour, S. J. (2012). Global, direct and diffuse solar radiation on horizontal and tilted surfaces in Jeddah, Saudi Arabia. Applied Energy, 87(1), 568-576.

[24] Elminir, H. K., Azzam, Y. A., \& Younes, F. I. (2007). Prediction of hourly and daily diffuse fraction using neural network, as compared to linear regression models. Energy, 32(1), 1513-1523. https://doi.org/10.1016/j.energy.2006.10.010 
[25] Cao, F., Li, H., Yang, T., Li, Y., Zhu, T., \& Zhao, L. (2017). Evaluation of diffuse solar radiation models in Northern China: New model establishment and radiation sources comparison. Renewable Energy, 103(1), 708-720. https://doi.org/10.1016/j.renene.2016.11.004

[26] Aras, H., Balli, O., \& Hepbasli, A. (2006). Estimating the horizontal diffuse solar radiation over the Central Anatolia Region of Turkey. Energy Convers Manage, 47(1), 22402249. https://doi.org/10.1016/j.enconman.2005.11.024

[27] Tarhan, S. \& Sari, A. (2005). Model selection for global and diffuse radiation over the Central Black Sea (CBS) region of Turkey. Energy Convers Manage, 46(4), 605-613. https://doi.org/10.1016/j.enconman.2004.04.004

[28] Ulgen, K. \& Hepbasli, A. (2009). Diffuse solar radiation estimation models for Turkey's big cities. Energy Convers Manage, 50(1), 149-156. https://doi.org/10.1016/j.enconman.2008.08.013

[29] Tirıs, M., Tırıs, Ç., \& Türe, İ. E. (1996). Correlations of monthly - average daily global, diffuse and beam radiations with hours of bright sunshine in Gebze, Turkey. Energy Convers Manage, 37(1), 1417-1421. https://doi.org/10.1016/0196-8904(95)00227-8

[30] Bakırc1, K. (2015). Models for the estimation of diffuse solar radiation for typical cities in Turkey. Energy, 82(1), 827838. https://doi.org/10.1016/j.energy.2015.01.093

[31] Ulgen, K. \& Hepbasli, A. (2003). Comparison of the diffuse fraction of daily and monthly global radiation for Izmir, Turkey. Energy Sources, 25(7), 637-649. https://doi.org/10.1080/00908310390212444

[32] Iqbal, M. (1983). An introduction to solar radiation. New York, USA: Academic Press.

[33] Duffie, J. A \& Beckman, W. A. (2006). Solar engineering of thermal processes, $3^{\text {rd }}$ ed. New York: John Wiley \& Son.

[34] Cooper, P. I. (1969). The absorption of solar radiation in solar stills. Solar Energy, 12(3), 333-346. https://doi.org/10.1016/0038-092X(69)90047-4

[35] Montgomery, D. C., Peck E. A., \& Vining G. G. (2012). Introduction to Linear Regression Analysis. Wiley.

[36] Stone, R. J. (1993). Improved statistical procedure for the evaluation of solar radiation estimation models. Solar Energy, 51(4), 288-291.

https://doi.org/10.1016/0038-092X(93)90124-7

\section{Contact information:}

Ceyda Aksoy TIRMIKÇI, Research Assistant

Corresponding author

Sakarya University Eng. Faculty Electrical and Electronics Eng. Dept.,

Esentepe Campus, 54187, Serdivan, Sakarya, Turkey

Phone: +90264 2955632

E-mail: caksoy@sakarya.edu.tr

Cenk YAVUZ, Assistant Professor

Sakarya University Eng. Faculty Electrical and Electronics Eng. Dept.,

Esentepe Campus, 54187, Serdivan, Sakarya, Turkey

Phone: +90 2642955824

E-mail: cyavuz@sakarya.edu.tr 